\title{
Effect of alpha-lipoic acid antioxidant on sperm parameters and treatment of infertile men
}

\author{
Gholam Reza Akhavan farid ${ }^{1}$, Rana Ghandehari Alavijeh ${ }^{2}$, Erfaneh Shaygannia ${ }^{2}$, Marziyeh Tavalaee $^{3}$, Mohammad \\ Hossein Nasr-Esfahani ${ }^{4,5}$ \\ ${ }^{I}$ Research and Development Laboratory of Raha Pharmaceutical Company, Isfahan, Iran \\ ${ }^{2}$ PhD Candidate, Department of Reproductive Biotechnology, Reproductive Biomedicine Research Center, Royan \\ Institute for Biotechnology, ACECR, Isfahan, Iran \\ ${ }^{3}$ Assistant Professor, Department of Reproductive Biotechnology, Reproductive Biomedicine Research Center, Royan \\ Institute for Biotechnology, ACECR, Isfahan, Iran \\ ${ }^{4}$ Professor, Department of Reproductive Biotechnology, Reproductive Biomedicine Research Center, Royan Institute for \\ Biotechnology, ACECR, Isfahan, Iran \\ ${ }^{5}$ Professor, Isfahan Fertility and Infertility Center, Isfahan, Iran
}

\begin{abstract}
Background: Today, infertility is a problem that affects about $15 \%$ of couples due to male factors, female factors or both. High levels of oxidative stress, because of an imbalance between the reactive oxygene species and the antioxidant capacity, have been repeatedly reported in infertile men, which can have a destructive effect on the spermatogenesis process. Antioxidant treatment can improve the effects of oxidative stress in spermatozoa. In this paper, the effect of alpha-lipoic acid as a water and fat-soluble antioxidant and its effect on sperm quality and treatment outcomes on infertile men is discussed.

Materials and methods: Published articles in Elseviour data-base, Iran doc, Scopus, Mag iran, Pubmed and google scular between 1988 and 2018 were collected baesd on key words. Repeated articles or ones with unsufficient content were omitted.

Results: Alpha-lipoic acid is considered as a new antioxidant in the infertility-treatment field, due to its unique aptitude compare to other common antioxidants, such as vitamin $\mathrm{E}$ and $\mathrm{C}$. This antioxidant can improve sperm motility, DNA damage and effective treatment results by removing free radicals and restoring antioxidant enzymes.

Conclusion: The use of alpha-lipoeic acid through applying assisted reproductive techniques such as culture medium, freezing, or varicocele therapy have satisfactory results in treatment.

Keywords: Infertility, Male, Antioxidants, Thioctic Acid (Alpha-lipoic acid), Spermatogenesis.

Cited as: Akhavan farid GR, Ghandehari Alavijeh R, Shaygannia E, Tavalaee M, Nasr-Esfahani MH. Effect of alpha-lipoic acid antioxidant on sperm parameters and treatment of infertile men. Medical Science Journal of Islamic Azad University, Tehran Medical Branch 2020; 30(1): 16-24.
\end{abstract}

Correspondence to: Mohammad Hossein Nasr-Esfahani

Tel: $+9895015682-031$

E-mail: mh.nasr-esfahani@royaninstitute.org

ORCID ID: 0000-0003-1983-3435

Received: 5 May 2019; Accepted: 26 May 2019 
مجله علوم يزشكى دانشكاه آزاد اسلامى

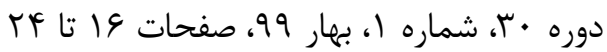

$\overline{\text { Systematic }}$

Review

\section{تاثير آنتى اكسيدان آلفا لييوئيك اسيد بر كيفيت هارامترهاى اسيرم و درمان مردان نابارور}

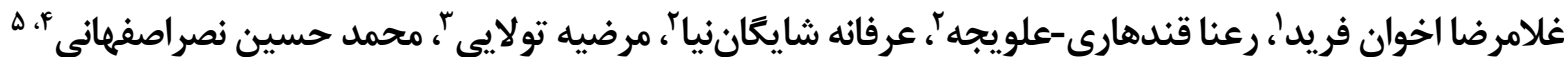

' ل داروساز عمومى، مركز تحقيقات و توسعه كارخانه داروسازى رها، اصفهان، ايران

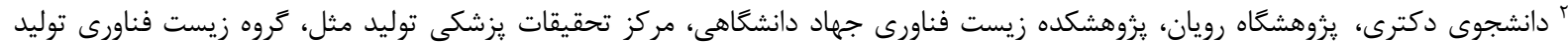

مثل، اصفهان، ايران

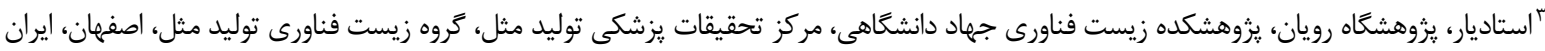

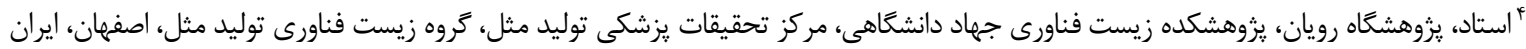

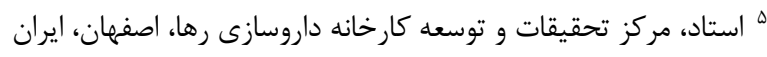

جكبده

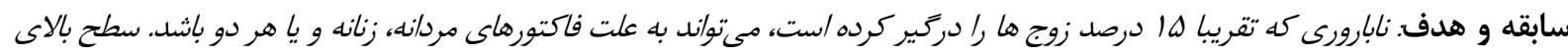

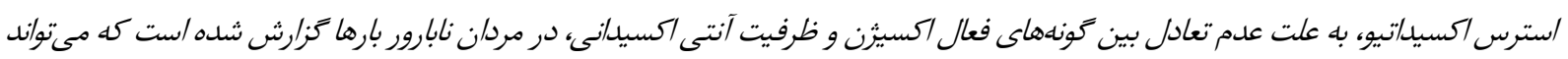

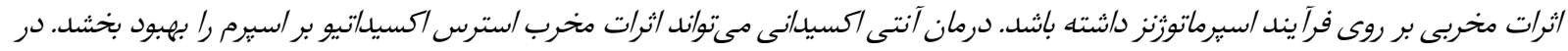

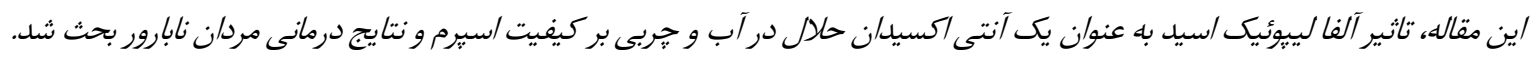

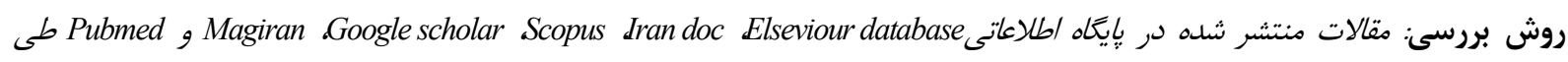

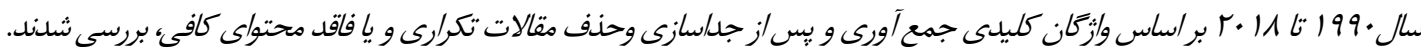

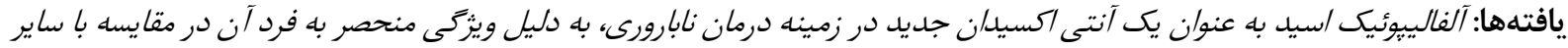

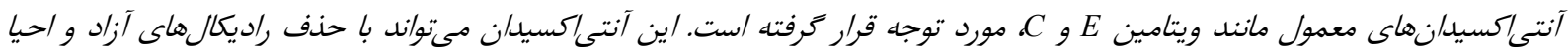

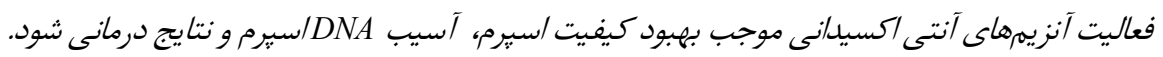

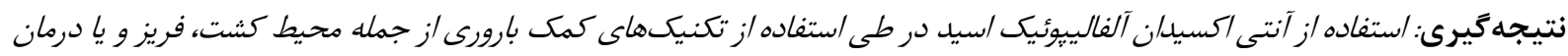
واريكوسل مىتواند نتايج رضايت بخشى را در درمان داشته باشند. وازخًان كليدى: نابارورى، مردان، آنتى اكسيد/نها، تيوكتيك /سيد (آلفاليبوئيك/سيد)، اسبرماتوزينز.

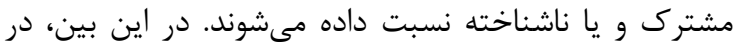
مقدمه

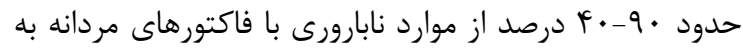
علت نقص در مراحل اسيرماتوزنز است كه منجر به توليد

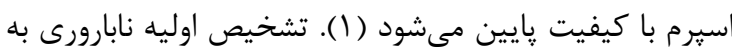
طور معمول بر اساس آناليز مايع منى صورت مى مئيرد.

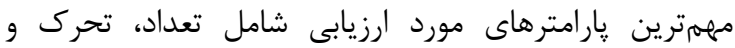
مورفولوزى اسيرم هاى موجود در مايع منى است (ك)). جهت

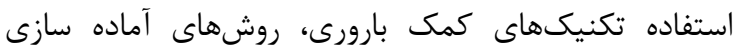
اسيرم با هدف حذف پِلاسما و اسيرمهاى غيرطبيعى استفاده

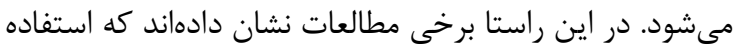
نابارورى به عدم دستيابى به حاملكَى يس از يك سال اقدام جهت بارورى بدون استفاده از روشهاى جلوكيرى اطلاق

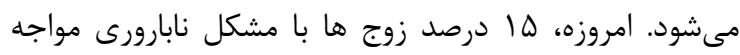
هستند. علل عدم دستيابى به حاملكَى به عوامل مردانه ،زنانه،

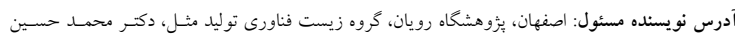

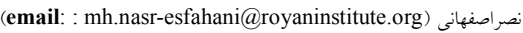
ORCID ID: 0000-0003-1983-3435 تاريخ دريافت مقاله:

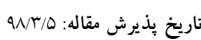




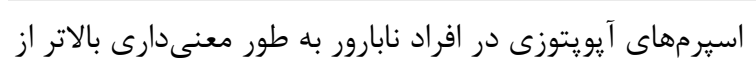

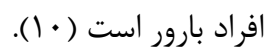
در شرايط عادى غلظت بالايى از آنتى اكسيدان در مايع منى و و إن)

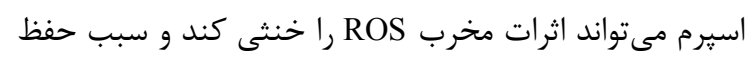

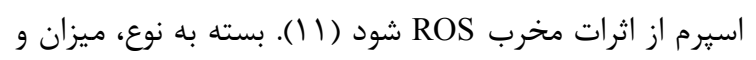

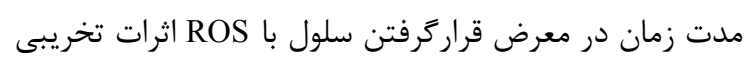

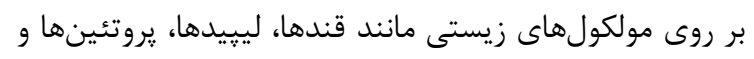
اسيدهاى نوكلئيك به وجود مي آيد.

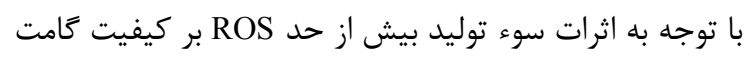

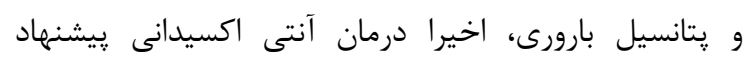

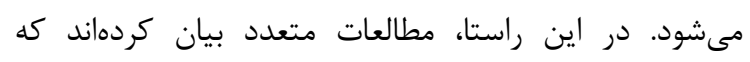

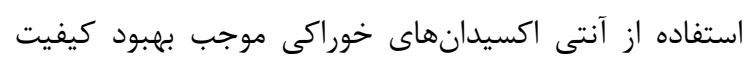

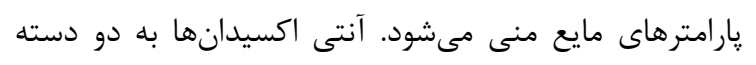

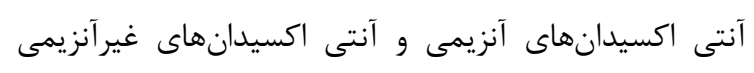

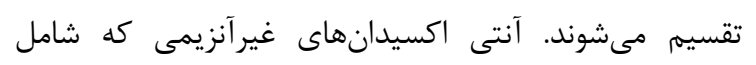

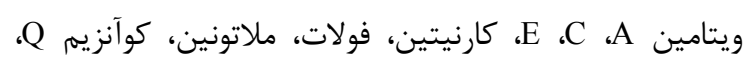

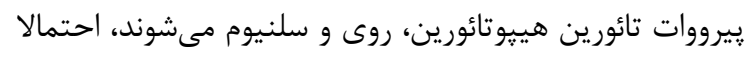
در بهبود بارورى نقش دارند (Y (I). در زمينه نابارورى مردان

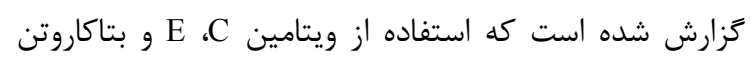

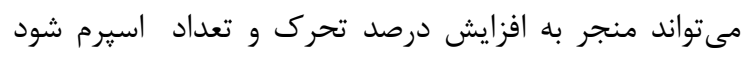
(rا1). آنتى اكسيدانهاى آنزيمى شامل سويراكسيد دسموتاز،

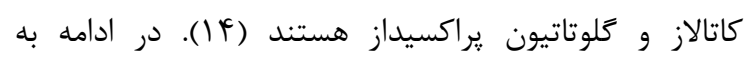

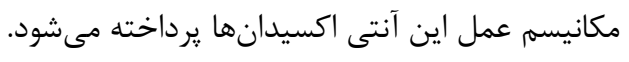

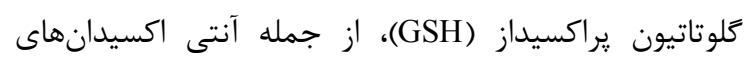

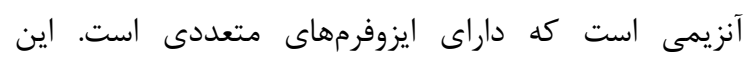

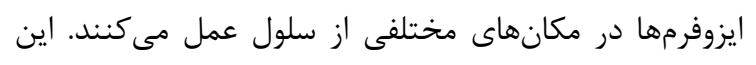

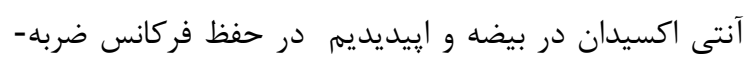

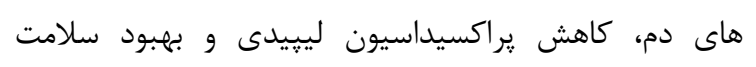

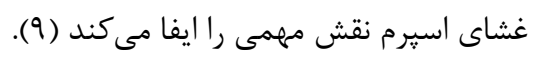

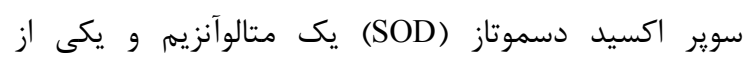
كارآمدترين آنزيمهاى آنتى اكسيدانى در بدن است كه ديد تبديل

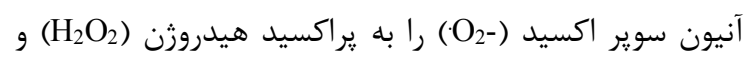
اكسيرن

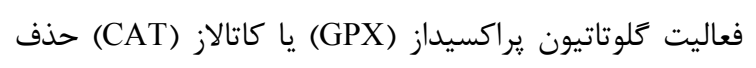

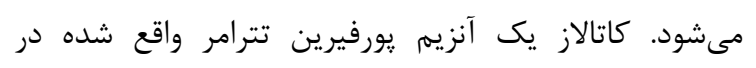

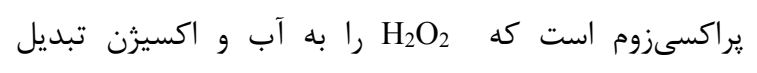

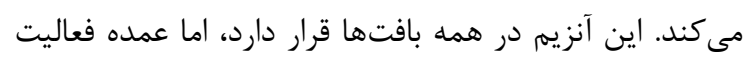

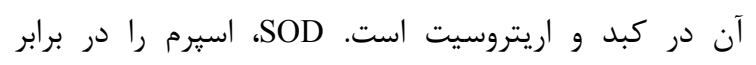

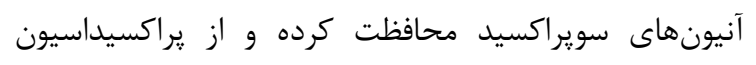

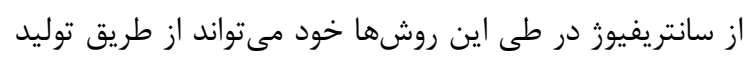

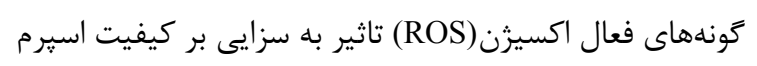

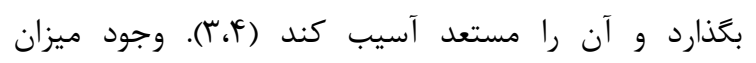

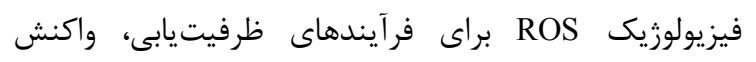

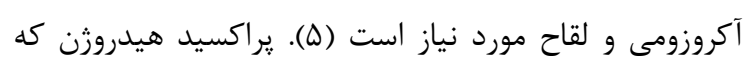

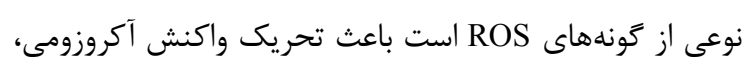

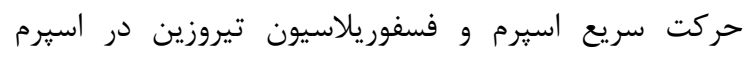

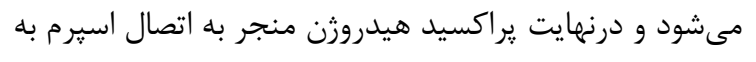

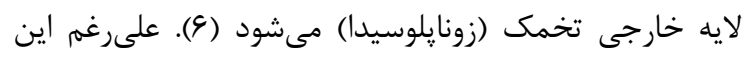

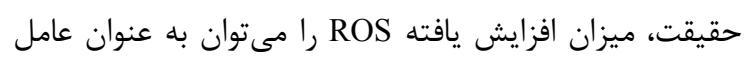

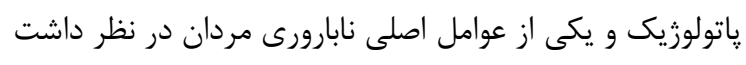

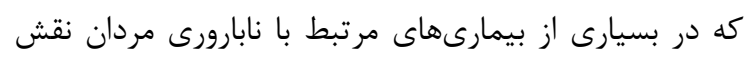

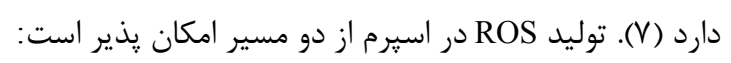

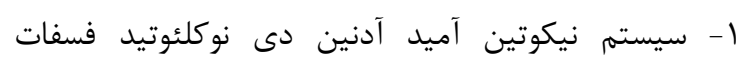

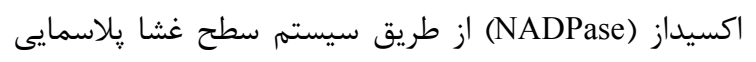

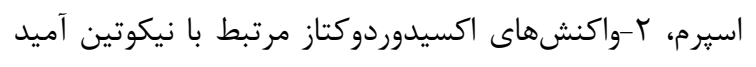

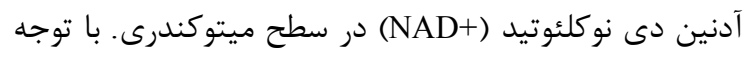

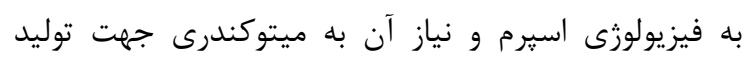

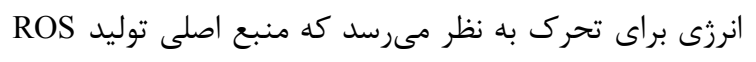

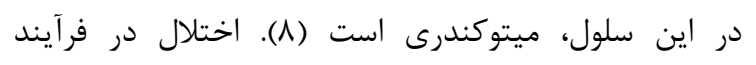

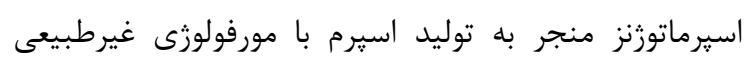

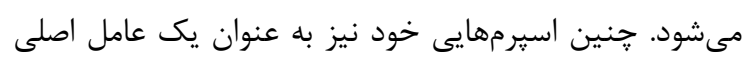

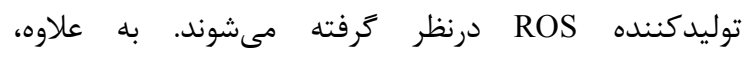

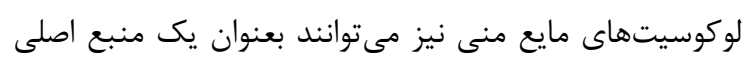

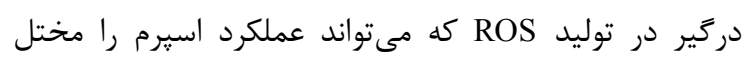

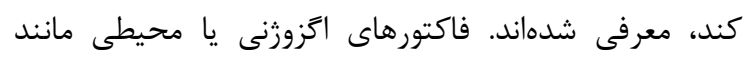

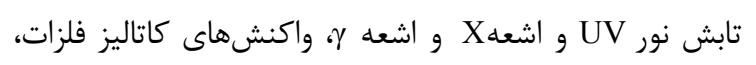

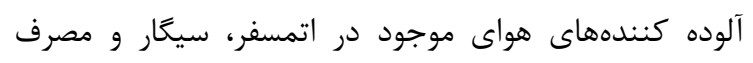

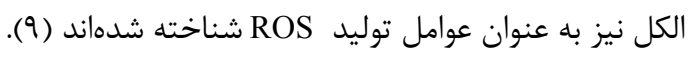
ROS

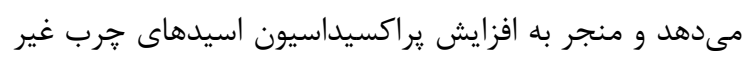

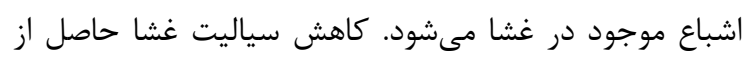

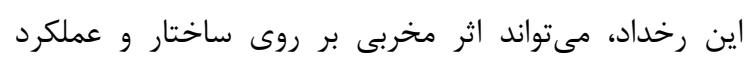

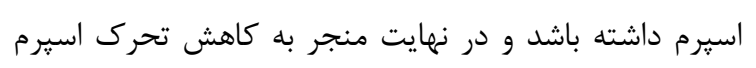

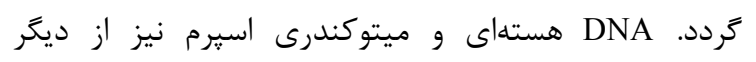

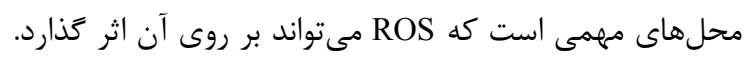

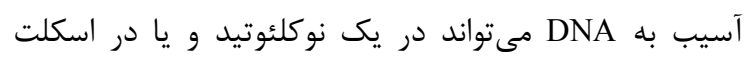

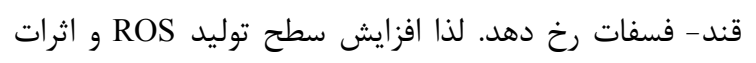

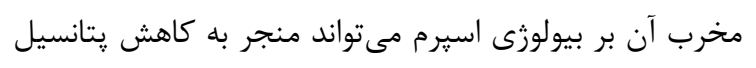

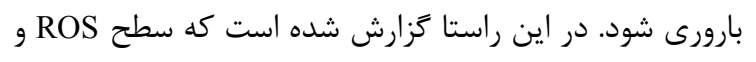




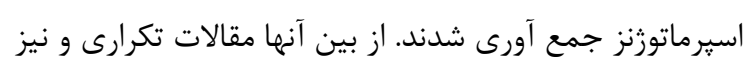

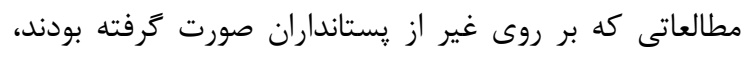

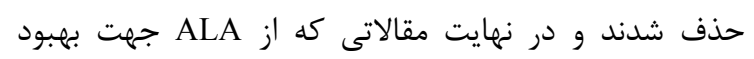

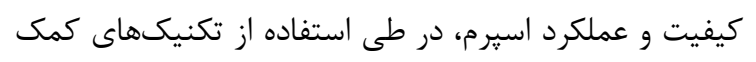

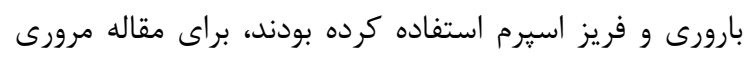

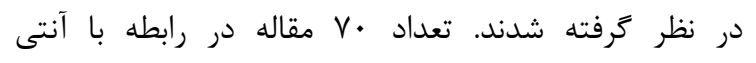

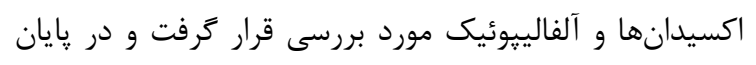
رץ مقاله در نغارش مطالعه حاضر مورد استفاده قرار كرفتند.

\section{يافتهها و بحث}

اسيد لييوئيك، از نظر شيميايى يك تركيب تئه تيولى است كه

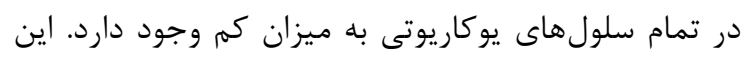

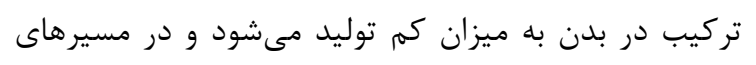
مختلف آنزيمى نقشهاى مهرمى را به به عهده دارد. براى انجام

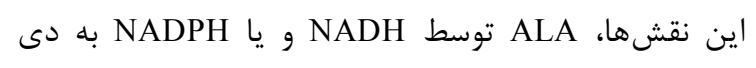

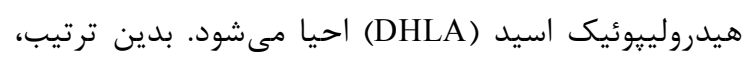

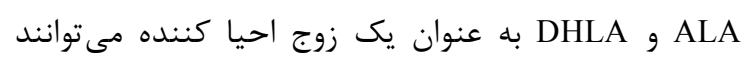

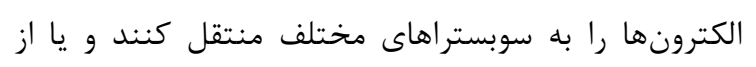

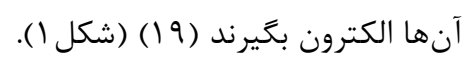

$\alpha$-Lipoic Acid

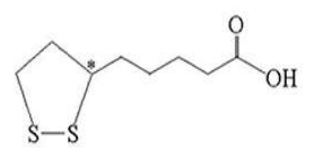

Oxidized

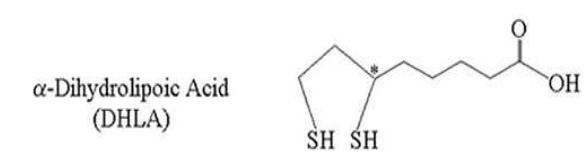

Reduced

*chiral (asymmetric) carbon

*Lipoic has a chiral center, which means it can be found in two mirror image forms (S- and R-a-lipoic acid) that cannot be superimposed on each other.

شكل ا. ساختار لييوئيك اسيد و دى هيدرولييوئيك اسيد (19).

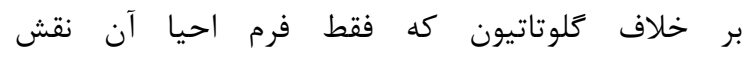

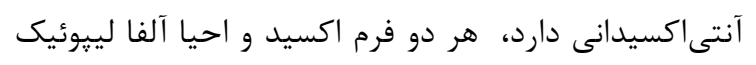

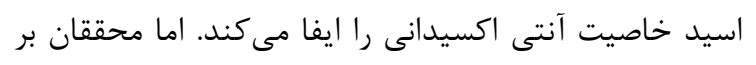

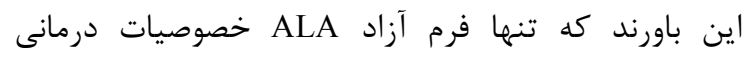

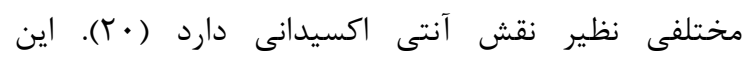

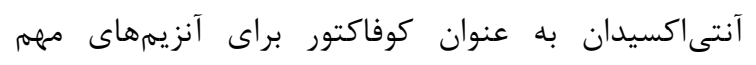

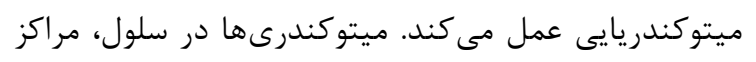

ليييدى جلوگيرى مى كند و نيز تحرك را بهبود مىبخشد

ويتامين E يا آلفا- توكوفرول يك آنتى اكسيدان قوى و

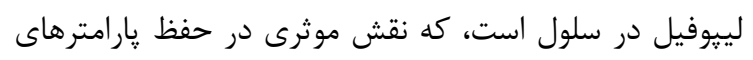

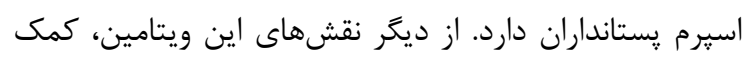

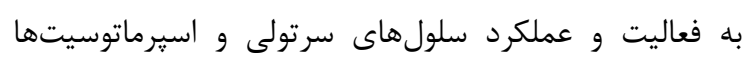

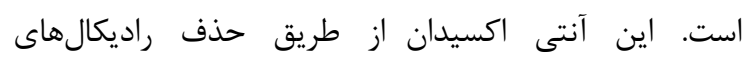

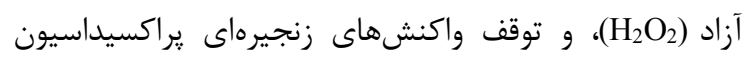
ليبيدى، مىتواند منجر به حفظ سلامت غشاء و تحرك اسيرم

شود (ه) (1ه).

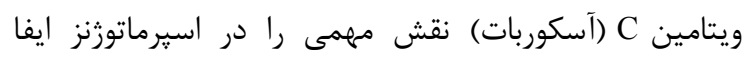

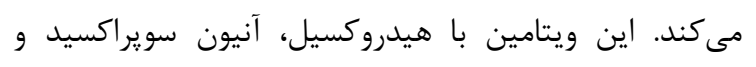

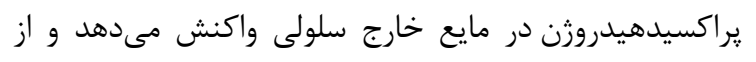
اثرات مخرب اين مولكولها بر حيات و تحرك اسيرم محافظت

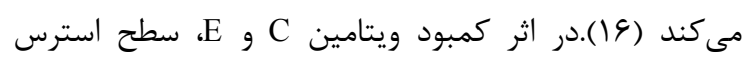

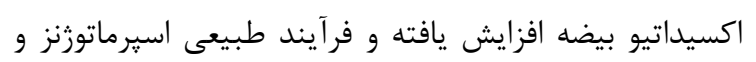
توليد تستوسترون مختل مىشود (IV)

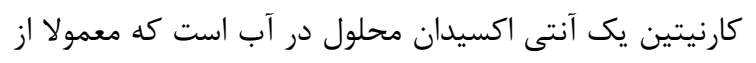

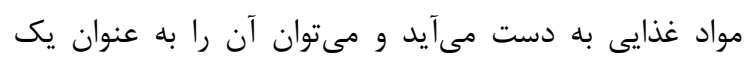

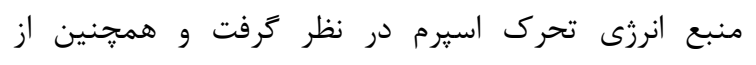

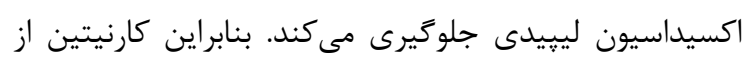

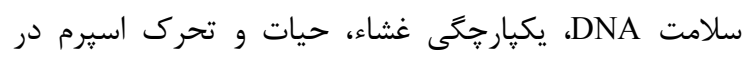
برابر اثرات استرس اكسيداتيو محافظت مى كند (1) (1).

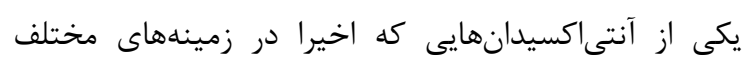

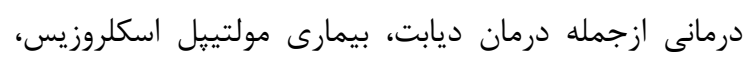

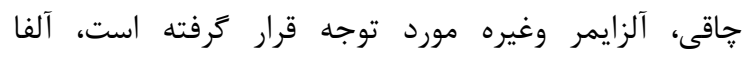

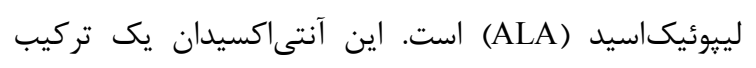

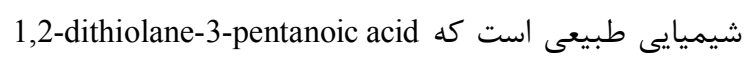

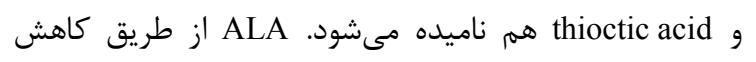

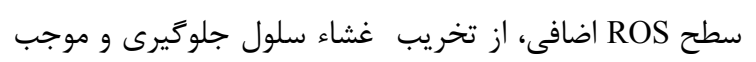

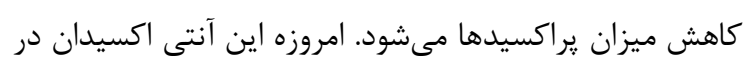
حوزه نابارورى مورد توجه قرار ترفته است.

\section{مواد و روشها}

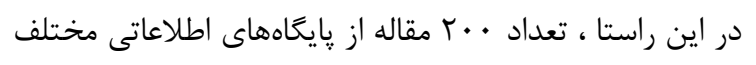
شامل Elseviour ، Iran doc، Scopus،Google scholar تا 199 Magiran ، database

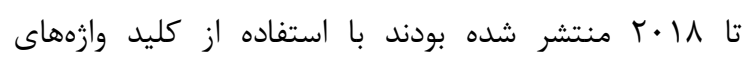

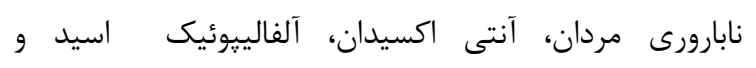




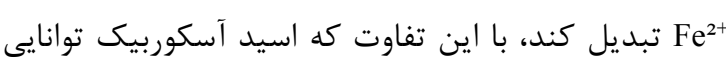

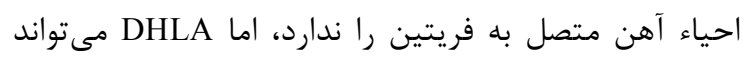

$$
\text { اين آهن را نيز احياء كند (باء مبن). }
$$

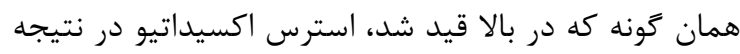

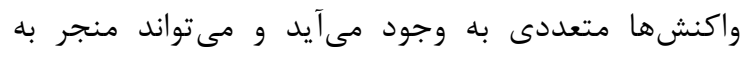

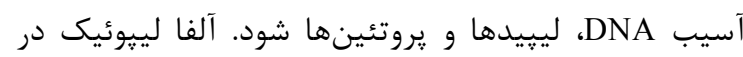

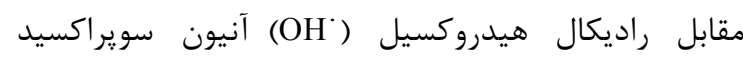
و كونهاى فعال نيتروزن مثل يراكسى نيترات و نيتريك اكسايد (NONOO)

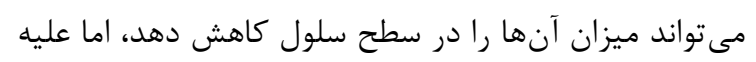

يراكسيد اكسيزن و سويراكسيدها فعاليتى ندارد (^).

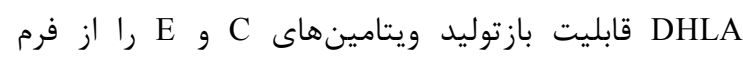

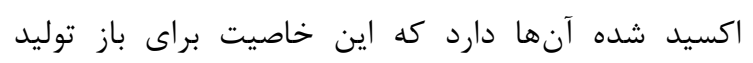

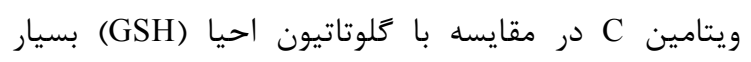
بيشتر است. هر خند كه توانايى احيا گروه تيول توسطا

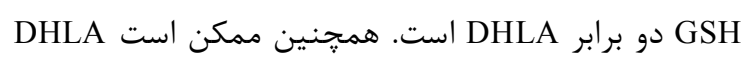

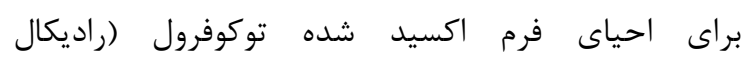

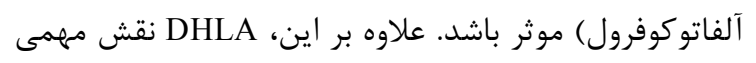

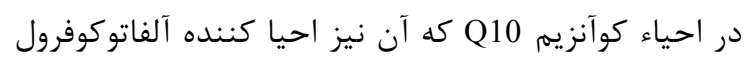

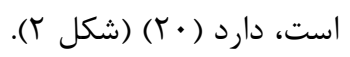

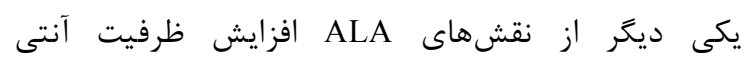

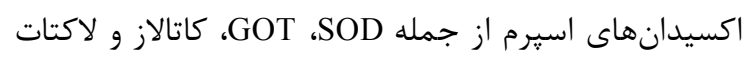

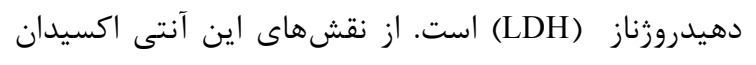

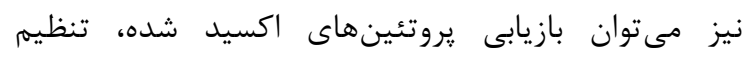

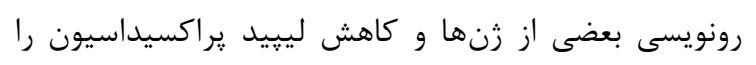

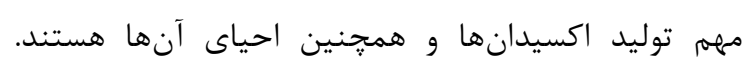

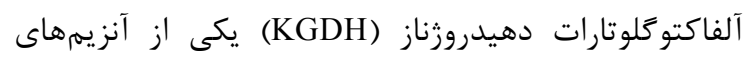

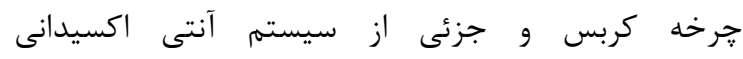

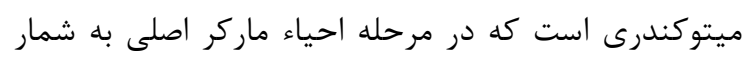

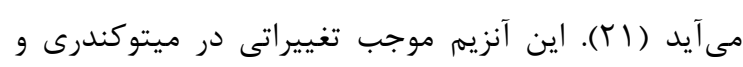

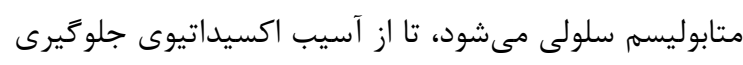

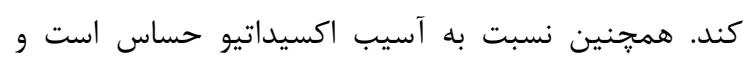
توسط واسطههاى راديكال آزاد مهار مئشود. لييوئيك اسيد آسيد

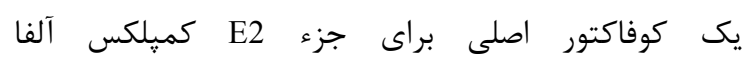

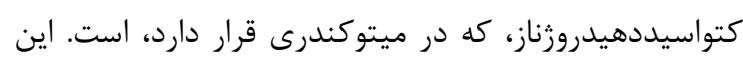

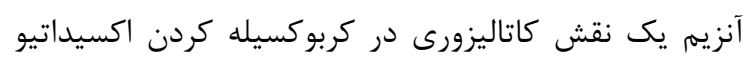

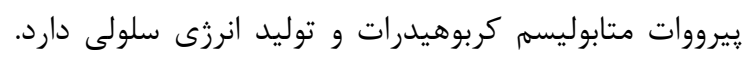
R- $\alpha$-LA ALA

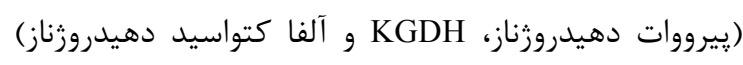

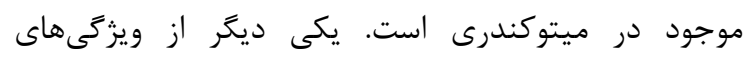

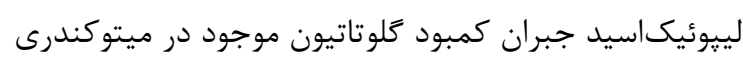

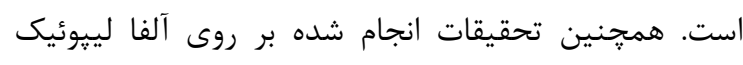

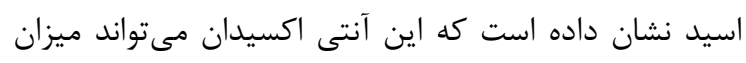
توليد كلوتاتيون را در سطح سلول بالا ببرد (Y (Y).

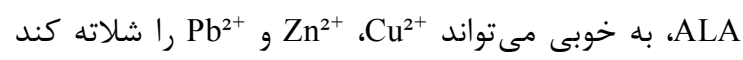
اما توانايى شلاته كردن ماند

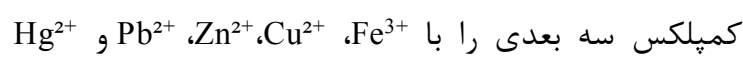

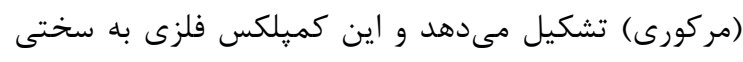

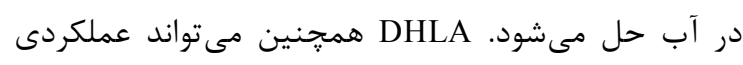

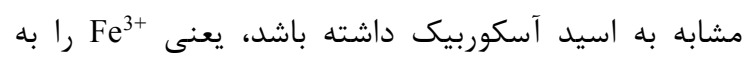

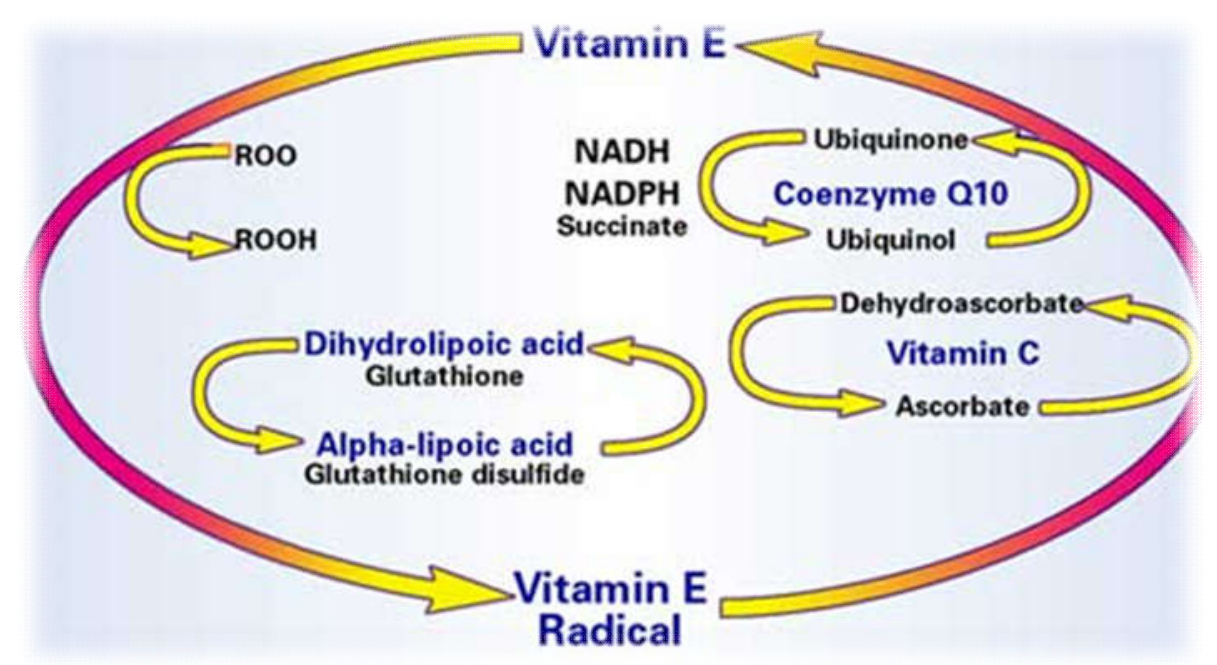

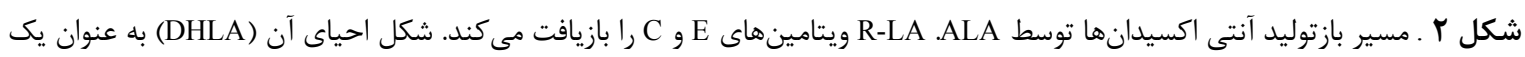

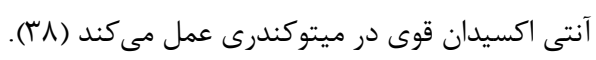


كاربرد آنتى اكسيدانها در روشهاى كمك بارورى

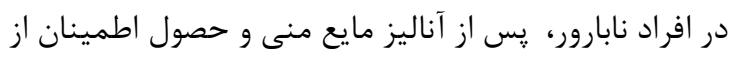

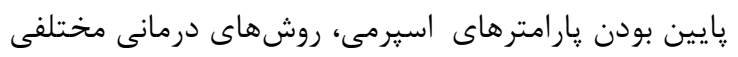

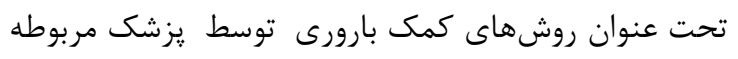

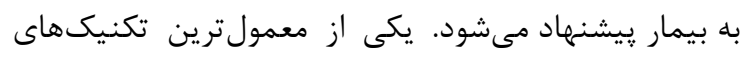

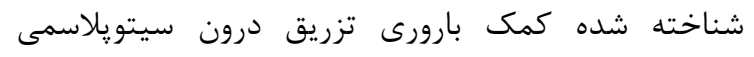

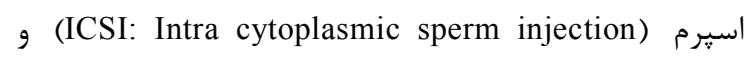
لقاح آزمايشعاهى (IVF: In-vitro fertilization) است. در تكنيك ICSI تمامى سدهايى كه در بارورى طبيعى و IVF

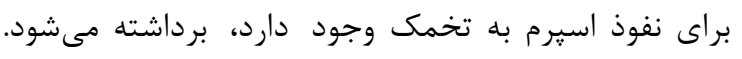

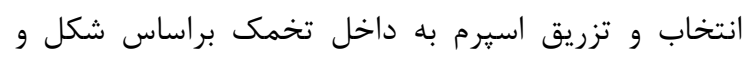

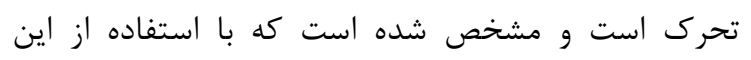
تكنيك ميزان لقاح و بارورى افزايش ميى يابد (َ).

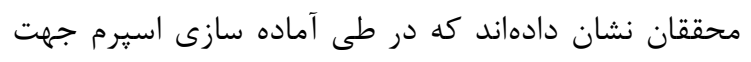

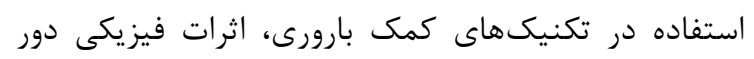

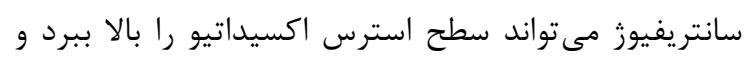

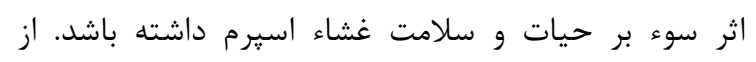

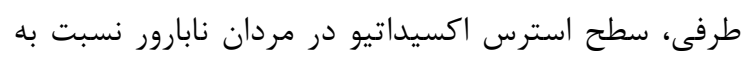

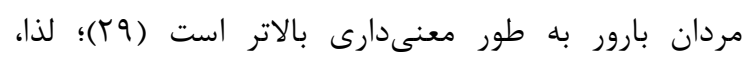

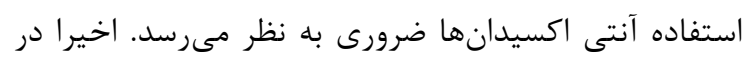

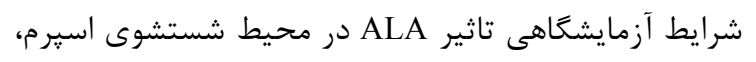

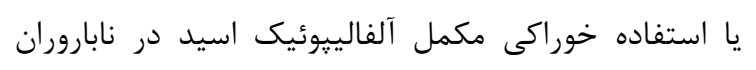

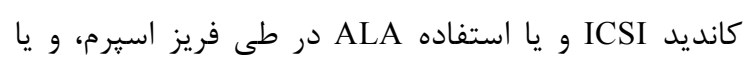

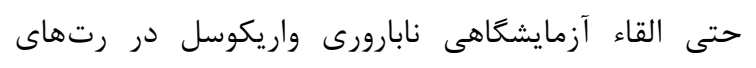

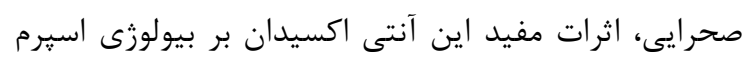

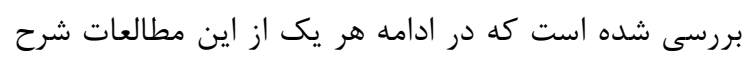

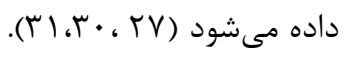

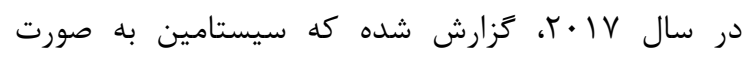

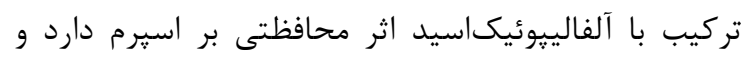

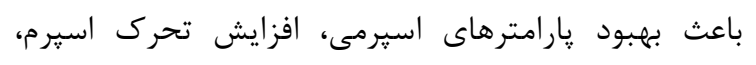

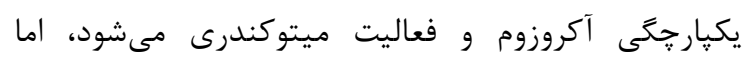

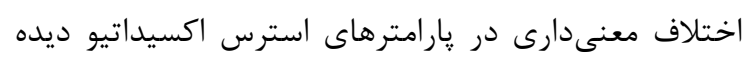

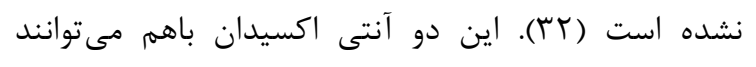

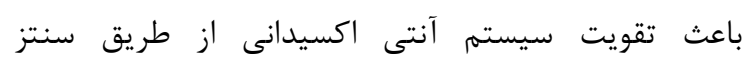

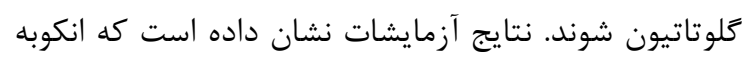

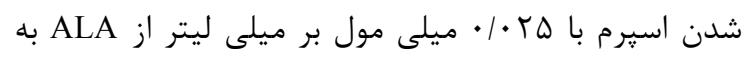

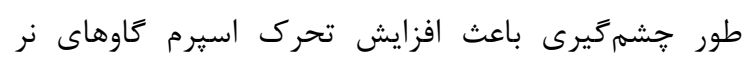

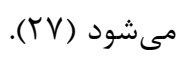

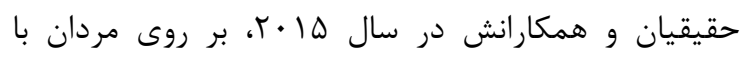

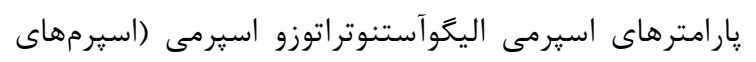

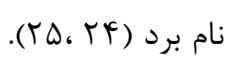

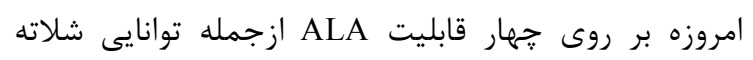

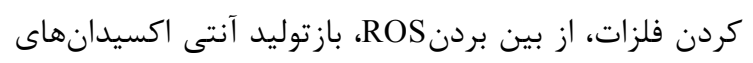

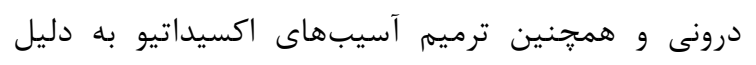

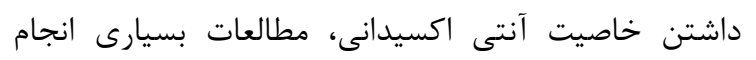

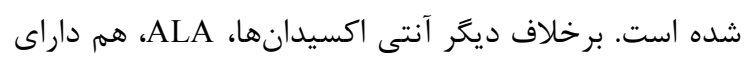

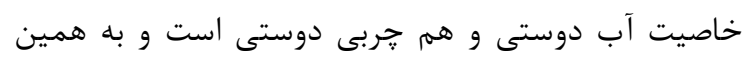

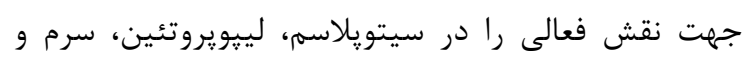

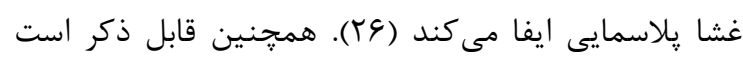
كه بين فعاليت يونهاى هيدروزن و تحرى إسى اسيرم ارتباط

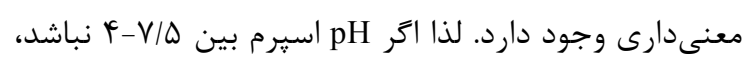

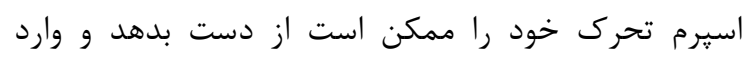

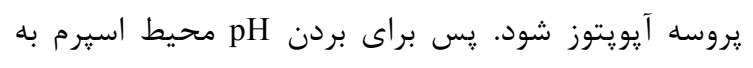

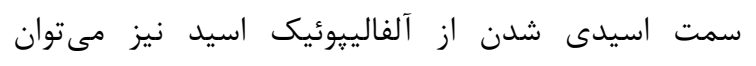

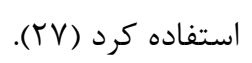

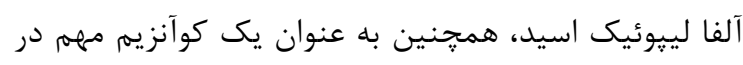

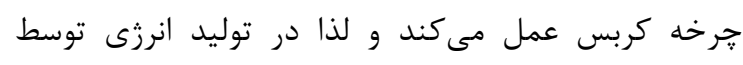

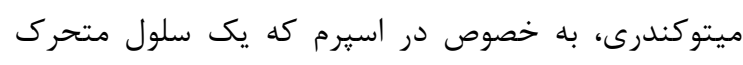

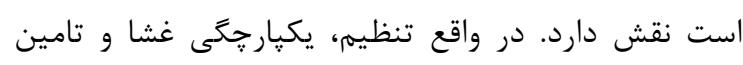
انرزى سه فاكتور مهمى هستند كه تحرى استى اسيرم به به آنها

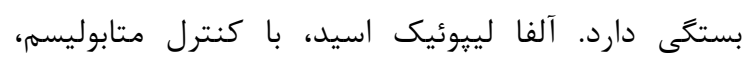

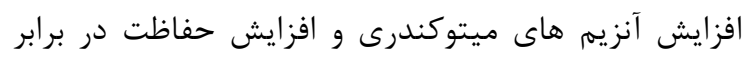

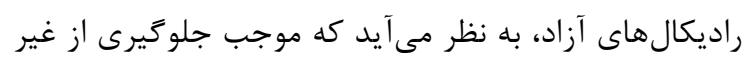

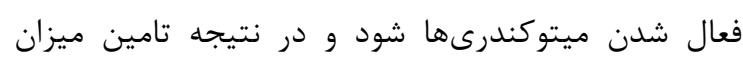

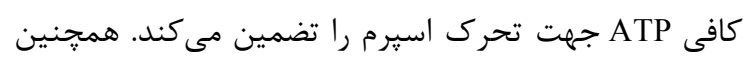

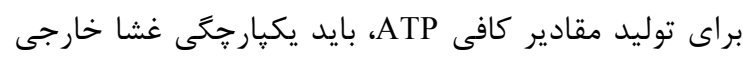

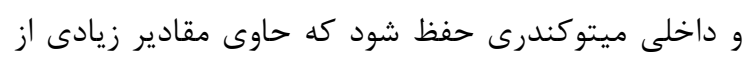

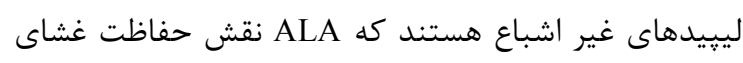
ميتوكندرى را نيز ايفا مى كند.

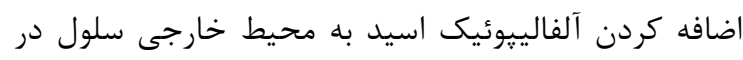

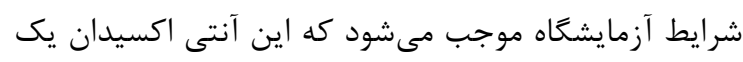

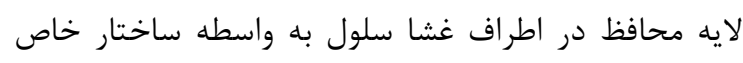

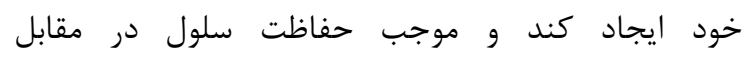

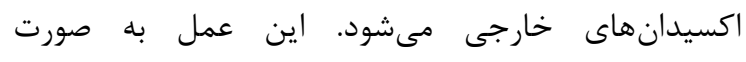

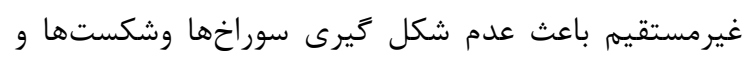

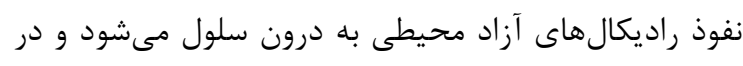

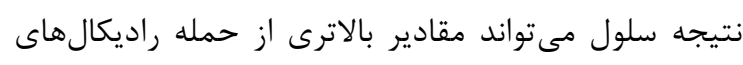

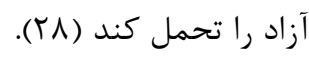




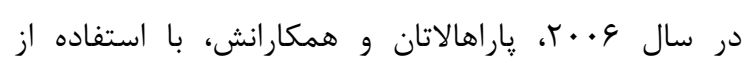

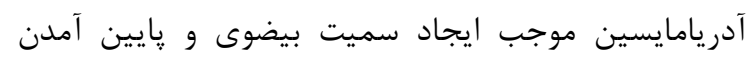

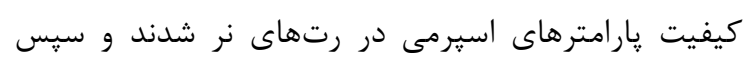

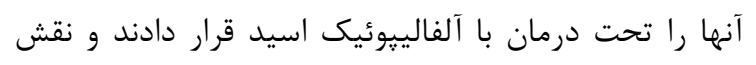

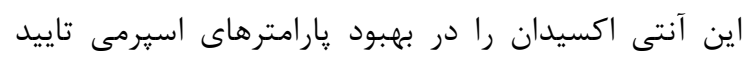

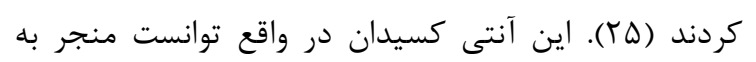

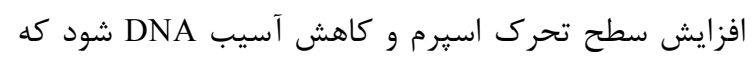

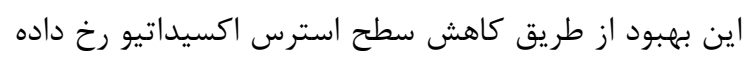

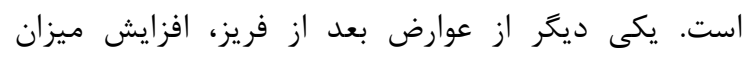

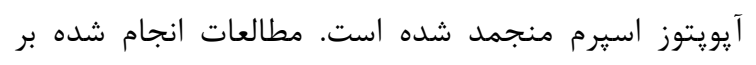

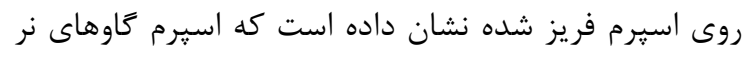

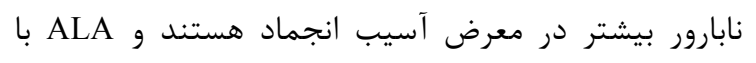

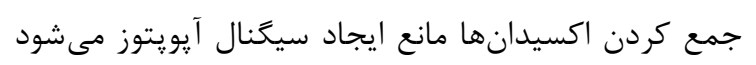

در پايان نتيجه گيرى مىشود كه مطالعات متعددى در آنتي

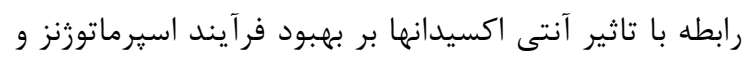

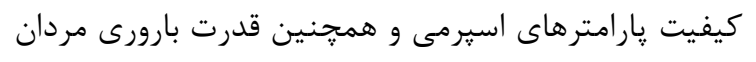
از طريق كاهش سطح استرس اكسيداتيو صورت كرفتهاند.

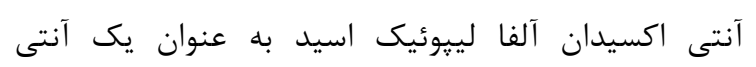

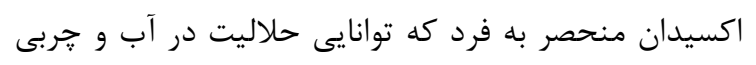

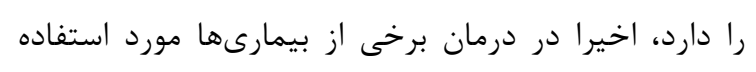

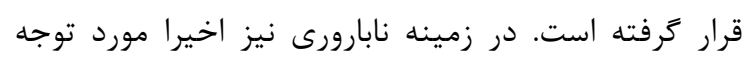

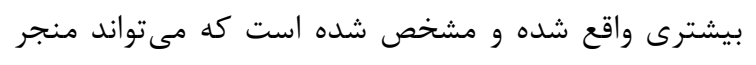

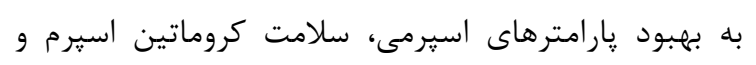
كاهش سطح ليبيديركسيداسيون اسيرم شود. با اين حال

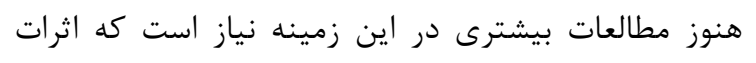

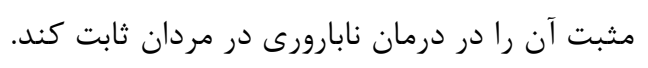

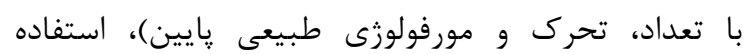

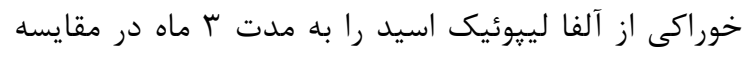

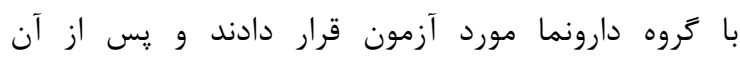

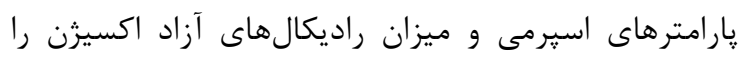

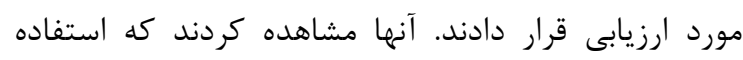

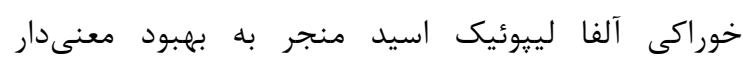

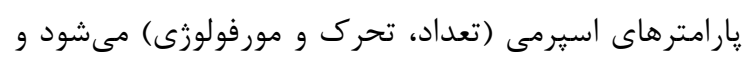

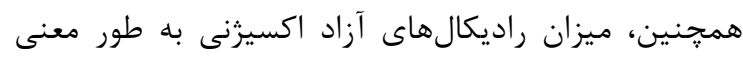

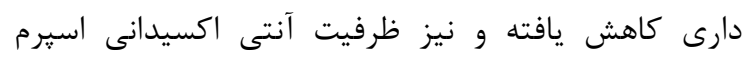

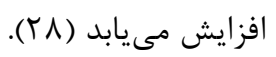

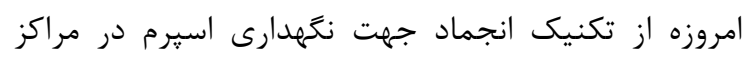

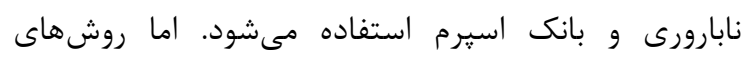

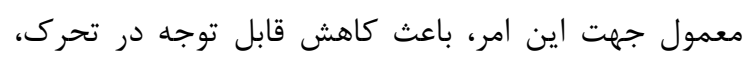

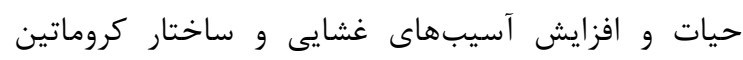

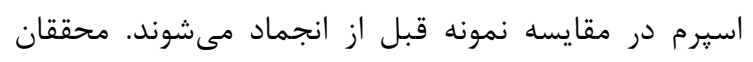

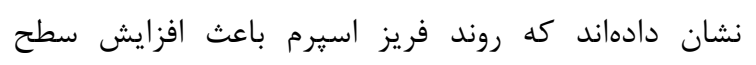

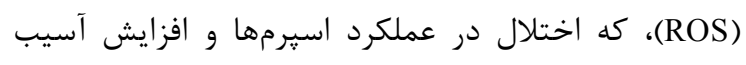

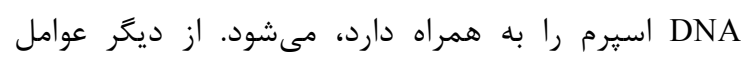

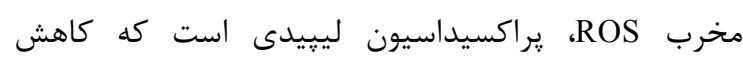

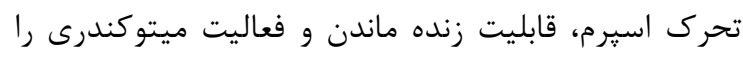

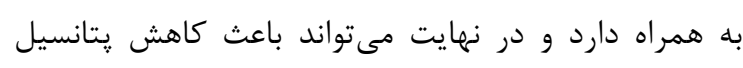

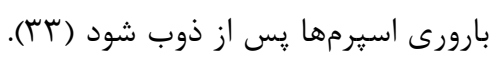

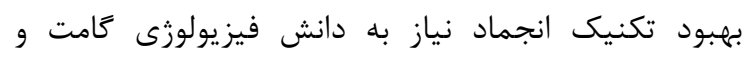

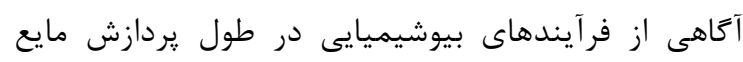

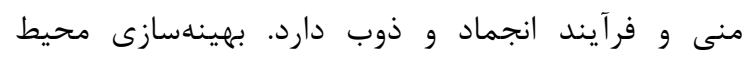

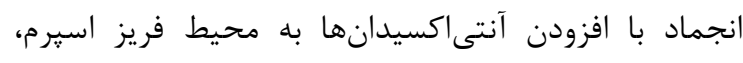

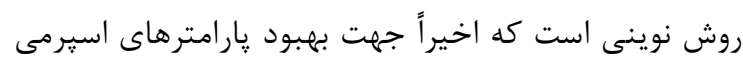

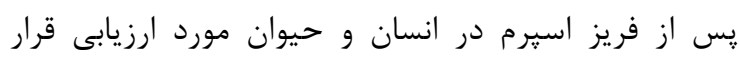

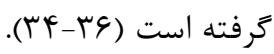

\section{REFERENCES}

1. Templeton A, Fraser C, Thompson B. The epidemiology of infertility in Aberdeen. BMJ 1990; 301: 148-52.

2- Nallella KP, Sharma RK, Aziz N, Agarwal A. Significance of sperm characteristics in the evaluation of male infertility. Fertil Steril 2006; 85: 629-34.

3- Nasr-Esfahani MH, Tavalaee M. Sperm selection for ICSI using the hyaluronic acid binding assay. Methods Mol Biol 2013; 927: 263-68.

4- Nasr-Esfahani MH, Deemeh MR, Tavalaee M. New era in sperm selection for ICSI. Int J Androl 2012; 35: $475-84$.

5- Aitken RJ. Oxidative stress and the etiology of male infertility. J Assist Reprod Genet 2016; 33: 1691-92.

6- Desai N, Sharma R, Makker K, Sabanegh E, Agarwal A. Physiologic and pathologic levels of reactive oxygen species in neat semen of infertile men. Fertil Steril 2009; 92: 1626-31.

7- Gharagozloo P, Aitken RJ. The role of sperm oxidative stress in male infertility and the significance of oral antioxidant therapy. Hum Reprod 2011; 26: 1628-40. 
8- Koppers AJ, De Iuliis GN, Finnie JM, McLaughlin EA, Aitken RJ. Significance of mitochondrial reactive oxygen species in the generation of oxidative stress in spermatozoa. J Clin Endocrinol Metab 2008; 93: 3199-207.

9- Saalu LC. The incriminating role of reactive oxygen species in idiopathic male infertility: an evidence based evaluation. Pakistan J Biol Sci 2010; 13: 413.

10- Agarwal A, Virk G, Ong C, Du Plessis SS. Effect of oxidative stress on male reproduction. World J Mens Health 2014; 32: 1-17.

11- Walczak-Jedrzejowska R, Wolski JK, Slowikowska-Hilczer J. The role of oxidative stress and antioxidants in male fertility. Cent Eur J Urol 2013; 66: 60.

12- Pisoschi AM, Pop A. The role of antioxidants in the chemistry of oxidative stress. Eur J Med Chem 2015; 97: 5574.

13- Silver EW, Eskenazi B, Evenson DP, Block G, Young S, Wyrobek AJ. Effect of antioxidant intake on sperm chromatin stability in healthy nonsmoking men. J Androl 2005; 26: 550-56.

14- Shamsi MB, Venkatesh S, Kumar R, Gupta NP, Malhotra N, Singh N, et al. Antioxidant levels in blood and seminal plasma and their impact on sperm parameters in infertile men. Indian J Biochem Biophys 2010; 47: 38-43

15- Adami L, Berladin L, Lima B, Jeremias JT, Antoniassi MP, Okada FK, et al. Effect Of In Vitro Vitamin E (alphatocopherol) Supplementation In Human Sperm Submitted To Oxidative Stress. Andrology 2016; 4: 56.

16- Singh U, Rani A, Singhal P, Kumar N, Srivastava A. Protective role of vitamin C on sperm morphology and biochemical enzymes in lead nitrate treated albino rats. J Anat Soc India 2016;65:S92.

17- Johnson FC. The antioxidant vitamins. CRC Crit Rev Food Sci Nutr 1979; 11: 217-309.

18- Agarwal A, Sekhon LH. The role of antioxidant therapy in the treatment of male infertility. Hum Fertil (Camb) 2010;13: 217-25.

19- Li YX, Lim ST. Preparation of aqueous alpha lipoic acid dispersions with octenylsuccinylated high amylosestarch. Carbohydr Polym 2016;140: 253-9.

20- Biewenga GP, Haenen GRMM, Bast A. The pharmacology of the antioxidant lipoic acid. Gen Pharmacol 1997; 29: 315-31.

21- Bast A, Haenen G. Lipoic acid: a multifunctional antioxidant. Biofactors 2003; 17: 207-13.

22- Valdecantos MP, Pérez-Matute P, González-Muniesa P, Prieto-Hontoria PL, Moreno-Aliaga MJ, Martínez JA. Lipoic acid administration prevents nonalcoholic steatosis linked to long-term high-fat feeding by modulating mitochondrial function. J Nutr Biochem 2012; 23: 1676-84.

23- Suh JH, Moreau R, Heath S-HD, Hagen TM. Dietary supplementation with (R)- $\alpha$-lipoic acid reverses the agerelated accumulation of iron and depletion of antioxidants in the rat cerebral cortex. Redox Rep 2005; $10: 52-60$.

24- Shen T, Jiang Z-L, Li C-J, Hu X-C, Li QW. Effect of alpha-lipoic acid on boar spermatozoa quality during freezing--thawing. Zygote 2016; 24: 259-65.

25- Prahalathan C, Selvakumar E, Varalakshmi P. Lipoic acid modulates adriamycin-induced testicular toxicity. Reprod Toxicol 2006; 21: 54-59.

26- Shay KP, Moreau RF, Smith EJ, Smith AR, Hagen TM. Alpha-lipoic acid as a dietary supplement: molecular mechanisms and therapeutic potential. Biochim Biophys Acta 2009; 1790: 1149-60.

27- Ibrahim SF, Osman K, Das S, Othman AM, Majid NA, Rahman MP. A study of the antioxidant effect of alpha lipoic acids on sperm quality. Clinics 2008; 63: 545-50.

28- Haghighian KH, Haidari F, Mohammadi-asl J, Dadfar MR. A randomized, triple-blind, placebo-controlled clinical trial examining the effects of alpha-lipoic acid supplement on the spermatogram and seminal oxidative stress in infertile men. Fertil Steril 2015; 104: 318-24.

29- Aitken RJ, Clarkson JS. Significance of reactive oxygen species and antioxidants in defining the efficacy of sperm preparation techniques. J Androl 1988; 9: 367-76.

30- Shay KP, Moreau RF, Smith EJ, Smith AR, Hagen TM. Alpha-lipoic acid as a dietary supplement: molecular mechanisms and therapeutic potential. Biochim Biophys Acta $2009 ; 1790: 1149-60$.

31-Shaygannia E, Tavalaee M, Akhavanfarid GR, Rahimi M, Dattilo M, Nasr-Esfahani MH. Alpha-Lipoic Acid improves the testicular dysfunction in rats induced by varicocele. Andrologia 2018; 50: 13085. 
32- Gungur S, Aksoy A, Yeni D, Avdatek F, Ozturk C, Bozkurt ataman M, et al. Combination of Cysteamine and Lipoic Acid Improves the Post-Thawed Bull Sperm Parameters. Kocatepe Vet J 2016; 9: 88-96.

33- Bateni Z, Azadi L, Tavalaee M, Kiani-Esfahani A, Fazilati M, Nasr-Esfahani MH. Addition of Tempol in semen cryopreservation medium improves the post-thaw sperm function. Syst Biol Reprod Med 2014; 60: 245-50.

34- Azadi L, Tavalaee M, Deemeh MR, Arbabian M, Nasr-Esfahani MH. Effects of tempol and quercetin on human sperm function after cryopreservation. Cryo Letters 2017; 38: 29-36.

35- Hezavehei M, Sharafi M, Kouchesfahani H, Henkel R, Agarwal A, Esmaeili V, et al. Sperm cryopreservation: a review on current molecular cryobiology and advanced approaches. Reprod Biomed Online 2018; 37: $337-39$.

36- Maroei Millan T, Daghigh Kia H, Moghaddam Gh. Effects of different levels of Curcumin antioxidant in Beltsville modified diluent on rooster sperm quality after freeze-thawing process. Journal of Animal Science Researches 2017; 28: 65-76. [In Persian]

37- Martin G, Sabido O, Durand P, Levy R. Cryopreservation induces an apoptosis-like mechanism in bull sperm. Biol Reprod 2004;71: 28-37. 